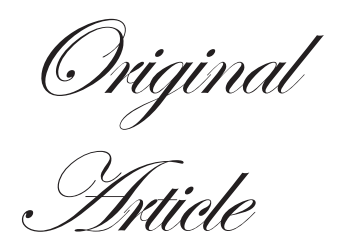

\title{
Frequency and factors associated with increased small intestinal permeability in patients with portal hypertension
}

\author{
Ajesh Goyal ${ }^{1}$, Uday C Ghoshal ${ }^{1}$, Imran Ahamad ${ }^{2}$, Raja Roy ${ }^{3}$, \\ Deepakshi Srivastava $^{1}$, Samir Mohindra ${ }^{1}$, Vivek A Saraswat ${ }^{1}$, CL \\ Khetrapal $^{3}$
}

ABSTRACT

Department of Gastroenterology ${ }^{1}$,

Aim: Cirrhosis with portal hypertension (PHT) may be associated with increased small intestinal Sanjay Gandhi Post Graduate Institute (SGPGI) of Medical Sciences and Center for Bio-Medical Research $(\mathrm{CBMR})^{3}$, SGPGI Campus, Lucknow 226104, India permeability (SIP), predisposing to malnutrition and bacterial translocation causing septicaemia, endotoxaemia and spontaneous bacterial peritonitis. However, data on SIP in extrahepatic portal venous obstruction (EHPVO), in which PHT occurs without hepatic dysfunction, are scanty. Such studies would help to know the effect of PHT on SIP independent of hepatic dysfunction; hence, we undertook this study.

Methods: A total of 96 patients with PHT (cirrhosis 71, EHPVO 25) underwent evaluation of

Correspondence:

Dr Uday C. Ghoshal

Email: udayghoshal@gmail.com

SIP using urinary lactulose/mannitol excretion ratio over 6 hours after oral administration of $15 \mathrm{~mL}(10 \mathrm{~g})$ lactulose and $5 \mathrm{~g}$ mannitol using $1 \mathrm{H}-\mathrm{NMR}$ spectroscopy by a method described by us previously.

Results: Gender of patients with EHPVO and cirrhosis was comparable but patients with EHPVO were younger in age. The causes of cirrhosis were cryptogenic $(n=22)$, alcohol $(n=20)$, post-viral $(n=21)$ and others $(n=8)$. Twenty-seven $(38 \%)$ patients with cirrhosis had ascites. Abnormal SIP was detected in 47 (49\%) patients (40/71, 56\% with cirrhosis vs. 7/25, 28\% with EHPVO, $\mathrm{p}=0.01$ ). Patients with cirrhosis had a higher urinary lactulose/mannitol excretion ratio than those with $\mathrm{EHPVO}(0.09$, range $0-0.87 \mathrm{mmol}$ vs. $0.05,0-0.19 \mathrm{mmol} ; \mathrm{p}=0.008)$. Patients with abnormal SIP had a higher Child score, and more often had cirrhosis than EHPVO, ascites and deranged liver function. On multivariate analysis, presence of cirrhosis, ascites, high serum bilirubin level and prothrombin time were associated with abnormal SIP.

Conclusions: Cirrhosis was associated with abnormal SIP, which was related to liver dysfunction. However, SIP was normal in patients with EHPVO.

KEYWORDS: portal vein, cirrhosis, $1 \mathrm{H}-\mathrm{NMR}$ spectroscopy, lactulose/mannitol ratio, small intestinal permeability

\section{Introduction}

Intestinal permeability is the property of a membrane that enables the passage of solutes by unmediated diffusion. The function of intestinal mucosa is to act as a barrier to permeation of antigens and at the same time to facilitate the absorption of electrolytes and nutrients. Increased small intestinal permeability (SIP) has been implicated in the pathogenesis of (C) Tropical Gastroenterology 2013 various diseases such as autoimmune diseases, ${ }^{1}$ coeliac disease, ${ }^{2}$ Crohn's disease, ${ }^{3}$ irritable bowel syndrome ${ }^{4}$ and tropical sprue. ${ }^{5}$

SIP is increased in patients with cirrhosis. ${ }^{6-9}$ Increased SIP may predispose to malnutrition and bacterial translocation leading to endotoxaemia, septicaemia and spontaneous 
bacterial peritonitis. Patients with advanced cirrhosis with encephalopathy, ${ }^{10}$ ascites ${ }^{11}$ and spontaneous bacterial peritonitis ${ }^{12}$ are more likely to have abnormal SIP. In a study on patients with cirrhosis, ${ }^{11}$ higher SIP (as determined by PEG 3350 excretion) was found in Child-Pugh class $\mathrm{C}$ patients than in class A or B. In another study, ${ }^{8}$ intestinal permeability $(51 \mathrm{Cr}-$ EDTA excretion) was increased in patients with alcoholic liver disease compared to those with post-viral cirrhosis. However, scanty data are available on the frequency and factors associated with increased SIP in patients with cirrhosis.

It is not clear whether portal hypertension (PHT) or hepatic dysfunction or both contribute to abnormal SIP in patients with cirrhosis, as it is difficult to demonstrate the contribution of these factors separately in such patients. In theory, PHT may by itself lead to mucosal oedema leading to abnormal intestinal permeability. ${ }^{13}$ However, there are scanty data on SIP in extrahepatic portal venous obstruction (EHPVO), in which PHT occurs without hepatic dysfunction. There is only one study on $\mathrm{EHPVO}^{14}$ on a small number of children. There is no study in adults with EHPVO. Such studies would help to know the effect of PHT on SIP independent of hepatic dysfunction. Hence, we undertook a study with the following aims: (i) to study SIP using urinary lactulose/mannitol excretion ratio in patients with cirrhosis of the liver as compared to EHPVO, (ii) frequency of increased SIP among these patients using a cutoff based on an earlier study by our group, and (iii) factors associated with increased SIP in these patients.

\section{Methods}

Study subjects

Ninety-six patients with PHT (cirrhosis 71, EHPVO 25) diagnosed by characteristic findings on clinical examination, liver function test, coagulation profile, serology, ultrasound and upper gastrointestinal endoscopy, attending the Gastroenterology outpatient clinic of a tertiary referral hospital in northern India were subjected to evaluation of SIP after obtaining informed consent. Patients with urinary tract infection, spontaneous bacterial peritonitis, hepatic encephalopathy, renal failure, uncontrolled diabetes mellitus, extrahepatic biliary obstruction and inflammatory bowel disease were excluded from the study. No patient received any substance that could affect intestinal permeability such as nonsteroidal anti-inflammatory drugs or alcohol in the past 2 weeks. The study protocol was approved by the Institutional Ethics
Committee.

\section{Sample collection}

The subjects were not allowed to consume milk or its products within 24 hours before the test as milk affects intestinal permeability. Next morning, a urine specimen was obtained after an overnight fast. Subsequently, $5 \mathrm{~g}$ D-mannitol and $10 \mathrm{~g}$ (15 $\mathrm{mL}$ ) lactulose (Duphalac ${ }^{\mathrm{TM}}$, Solvay Pharmaceuticals., Brussels, Belgium) was orally administered dissolved in $50 \mathrm{~mL}$ distilled water and the patient was allowed to drink water ad libitum 1 hour later. Patients were allowed to take a sugar-free diet after 2 hours. Urine was collected in preservative (sodium azide) till 6 hours after ingestion of lactulose and mannitol and the total volume of urine collected duing the next 6 hours was measured; $20 \mathrm{~mL}$ urine was stored at $-80{ }^{\circ} \mathrm{C}$ till further analysis for quantification of lactulose and mannitol using 1H-NMR spectroscopy according to a method described by us previously. ${ }^{15}$

\section{NMR experiments}

\section{Nuclear magnetic resonance (NMR) analysis}

From the total volume of urine of each patient, $3 \mathrm{~mL}$ was lyophilized using Heto LyoLab Lyophilizer (HETO Lyolab Freeze Dryer, UK), residue was dissolved in $500 \mathrm{~mL}$ deuterium oxide $\left(\mathrm{D}_{2} \mathrm{O}\right)$ and was directly taken in a $5 \mathrm{~mm}$ cleaned NMR tube. A re-usable sealed capillary tube containing $30 \mathrm{~mL}$ of $0.375 \%$ sodium salt of 3-trimethylsilyl-pripionic acid (TSP) in $\mathrm{D}_{2} \mathrm{O}$ was inserted into the NMR tube before recording the spectra. TSP served as a chemical shift reference as well as an internal standard for quantitative estimation, whereas $\mathrm{D}_{2} \mathrm{O}$ served as the "field-frequency lock". One-dimensional NMR experiments using single pulse sequence were performed at $800 \mathrm{MHz}$ with water suppression by pre-saturation. Spectral width used was $16447 \mathrm{~Hz}$, with time domain data points $64 \mathrm{~K}$. The flip angle of the radiofrequency pulse was $45^{\circ}$ with a total delay of 8.4 seconds to ensure maximum recovery of magnetization equilibrium between the scans. Typically, 512 scans were obtained for each sample and the resulting data were Fourier transformed after multiplying by an exponential window function using a line broadening function of $0.3 \mathrm{~Hz}$ and an Fourier transform (FT) size of $64 \mathrm{~K}$ points. NMR spectra of all the pre-test samples were also recorded under similar conditions in order to find the difference in the pre- and post-lactulose 
and mannitol urine spectra. The concentrations of lactulose and mannitol were expressed as millimoles (mmol). Urinary lactulose/mannitol excretion ratio (ratio of the concentration of lactulose and mannitol) was calculated and a cut-off value of 0.078 was taken as abnormal as determined in a previous study by our group. ${ }^{15}$

\section{Statistical analysis}

Statistical analysis was performed using SPSS 15.0 and R and Epicalc software version R2.9.0 (R development core team, Vienna, Austria). Continuous data were expressed as median and range. Continuous and categorical variables were analysed using Mann-Whitney U-test and Chi-square test with Yates correction as applicable, respectively. Inter-group comparison of more than two variables was performed using Kruskal-Wallis $\mathrm{H}$ test to compare non-parametric data. Parameters found significant by univariate analysis were analysed using a stepwise logistic regression method. A p value of less than 0.05 was taken as significant.

\section{Results}

Demographic and clinical characteristics of patients with cirrhosis and EHPVO

Table 1 summarizes the demographic, clinical and laboratory parameters of patients with cirrhosis $(n=71)$ and EHPVO $(n=25)$. Patients with EHPVO were younger in age than those with cirrhosis; however, gender was comparable in both the groups. Renal function as assessed by serum creatinine level was normal in all the patients. The causes of cirrhosis were cryptogenic $(n=22)$, alcohol $(n=20)$, post-viral $(n=21)$, BuddChiari syndrome $(n=3)$, primary biliary cirrhosis $(n=3)$ and others (autoimmune) $(\mathrm{n}=2)$. Twenty-seven $(38 \%)$ patients with cirrhosis and none with EHPVO had ascites at the time of inclusion into the study.

\section{H-NMR spectra of mannitol}

1H-NMR spectrum of mannitol contained strongly coupled multiplets covering a chemical shift range of 3.88-3.62 ppm (Figure 1). T1 relaxation time for resonance at $3.86(\mathrm{dd} 2 \mathrm{H})$ ppm, which was used for the quantification of mannitol in the urine, was found to be $819 \mathrm{~ms}$. The number of protons contribution to the signal at $3.86 \mathrm{ppm}$ was determined by
Table 1: Demographic, clinical and laboratory parameters of the subjects with EHPVO and cirrhosis

\begin{tabular}{|c|c|c|c|}
\hline Parameter (range) & $\begin{array}{l}\text { EHPVO } \\
(n=25)\end{array}$ & $\begin{array}{l}\text { Cirrhosis } \\
(n=71)\end{array}$ & p value* \\
\hline Age (years) & $34(15-73)$ & $40(16-54)$ & 0.000 \\
\hline Gender (Men, \%) & $18(72.0)$ & $52(73.2)$ & 0.905 \\
\hline \multicolumn{4}{|l|}{ Aetiology } \\
\hline Ethanol & 0 & 20 & \\
\hline Viral & 0 & 21 & \\
\hline Others & 0 & 30 & \\
\hline $\mathrm{Hb}(\mathrm{g} / \mathrm{dL})$ & $9.8(6.3-15.3)$ & $10.8(4.9-15.9)$ & 0.429 \\
\hline Oesophageal varices & $34(15-73)$ & $34(15-73)$ & \\
\hline $\mathrm{BMI}$ & $19.5(15.6-30.5)$ & $22.3(14.3-33.1)$ & 0.014 \\
\hline Serum albumin $(\mathrm{g} / \mathrm{dL})$ & $3.8(2.8-4.9)$ & $3.6(0.6-4.6)$ & 0.036 \\
\hline Serum bilirubin $(\mathrm{mg} / \mathrm{dL})$ & $0.9(0.2-1.3)$ & $1.6(0.1-25.0)$ & 0.000 \\
\hline $\begin{array}{l}\text { Aspartate amino- } \\
\text { transferase (IU/L) }\end{array}$ & $34(15-73)$ & $59(16-558)$ & 0.000 \\
\hline $\begin{array}{l}\text { Alanine amino- } \\
\text { transferase (IU/L) }\end{array}$ & $28(10-65)$ & $36(14-401)$ & 0.002 \\
\hline $\begin{array}{l}\text { Serum alkaline } \\
\text { phosphate (IU/L) }\end{array}$ & $34(15-73)$ & $34(15-73)$ & 0.000 \\
\hline $\begin{array}{l}\text { Prothrombin time } \\
\text { (seconds) }\end{array}$ & $14.2(11.2-15.9)$ & $15.2(10.5-64.0)$ & 0.002 \\
\hline $\begin{array}{l}\text { Serum creatinine } \\
(\mathrm{mg} / \mathrm{dL})\end{array}$ & $0.8(0.5-1.4)$ & $0.9(0.5-1.4)$ & 0.341 \\
\hline Child stage A/B/C & NA & $44 / 13 / 14$ & \\
\hline \multicolumn{4}{|c|}{$\begin{array}{l}\text { *Mann-Whitney U test for continous variables, chi-square for } \\
\text { categorical data }\end{array}$} \\
\hline \multicolumn{4}{|c|}{$\begin{array}{l}\text { EHPVO=extrahepatic portal venous obstruction; BMI=body mass } \\
\text { index; Hb=haemoglobin }\end{array}$} \\
\hline
\end{tabular}

recording the spectrum of known concentration of D-mannitol in $\mathrm{D}_{2} \mathrm{O}$ in the presence of external reference TSP.

\section{H-NMR spectra of lactulose}

1H-NMR spectrum of lactulose in $\mathrm{D}_{2} \mathrm{O}$ is shown in Figure 1. According to a previous study, lactulose in $\mathrm{D}_{2} \mathrm{O}$ showed the presence of three isomeric $\beta$-anomeric galactosyl protons-4O-(ß-D-galactopyranosyl)-B-D-fructopyranose, 4-O-( $(-D-$ galactopyranosyl)- $\beta$-D-fructofuranose and 4-O-( $(-D-$ galactopyranosyl)-á-D-fructofuranose at 4.48, 4.39 and 4.37 ppm, respectively in a ratio of 66:25:9 with reference to monodenterium oxide (HDO) signal in $\mathrm{D}_{2} \mathrm{O}$ solution. ${ }^{9}$ Since overlapping of urine metabolites in the above mentioned chemical shifts were observed, therefore, the $\mathrm{H}-5$ of $\mathrm{B}$-anomeric galactosyl protons of 4-O- $\beta$-D-galactopyranosyl moiety of lactulose resonating at 4.13-4.14 ppm (broad signal) with respect to TSP calibrated at $0.0 \mathrm{ppm}$ and representing $66.0 \%$ 

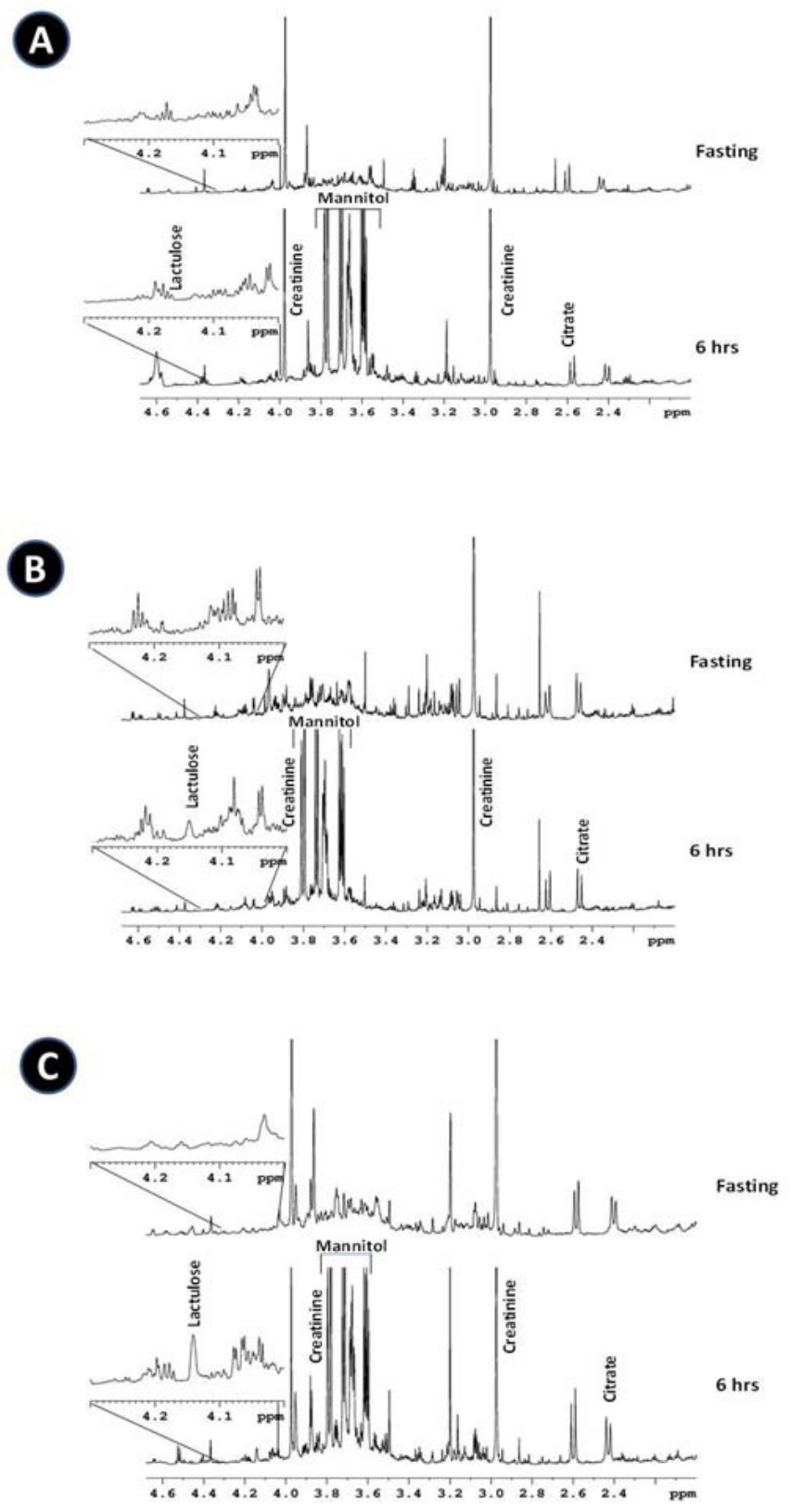

Figure 1: (A) 1H-NMR urine spectra of a patient with EHPVO in fasting state and 6 hours after ingestion of lactulose and mannitol. (B) 1H-NMR urine spectra of a patient with cirrhosis in fasting state and 6 hours after ingestion of lactulose and mannitol. (C) 1H-NMR urine spectra of a patient with cirrhosis with ascites at fasting state and 6 hours after ingestion of lactulose and mannitol. Note that the spectra in the region from 4.2 to $4.1 \mathrm{ppm}$ have been magnified four times to show lactulose excretion, which is more in the cirrhotic patient with ascites.

and $9.0 \%$ of the two isomers $(75 \%)$ of the isomeric forms, respectively were used for the quantification of lactulose excreted in urine. ${ }^{16}$ The number of protons contributing to the signal at $4.2 \mathrm{ppm}$ was determined by recording the known concentration of lactulose spectrum in $\mathrm{D}_{2} \mathrm{O}$ in the presence of external reference TSP.
Urinary excretion of lactulose, mannitol and its ratio in patients with EHPVO and cirrhosis

As shown in Table 2, patients with cirrhosis excreted a higher quantity of lactulose in urine (median 0.87 , range $0-20.32 \mathrm{mmol}$ vs. median 0.28 , range $0-1.93 \mathrm{mmol}, \mathrm{p}=0.007$ ) and had a higher urinary lactulose/mannitol excretion ratio than those with EHPVO (median 0.09 , range $0-0.87 \mathrm{mmol}$ vs. median 0.05 , range $0-0.19 \mathrm{mmol}, \mathrm{p}=0.008$ ). Abnormal SIP was detected in 47 of 96 (49\%) patients (40/71, 56\% with cirrhosis vs. $7 / 25,28 \%$ with EHPVO, $\mathrm{p}=0.01$ ) according to a cut-off reported by our group previously. ${ }^{15}$

Urinary excretion of lactulose, mannitol and its ratio in patients with cirrhosis with or without ascites

Excretion of lactulose (median 1.29, range 0-20.33 mmol vs. median 0.54 , range $0-15.58 \mathrm{mmol}$; $\mathrm{p}=\mathrm{ns}$ ) and mannitol (median 10.09 , range $0-100.82 \mathrm{mmol}$ vs. median 12.06 , range $0.61-68.49$ $\mathrm{mmol} ; \mathrm{p}=\mathrm{ns}$ ) was comparable in cirrhotic patients with and without ascites. However, urinary lactulose/mannitol excretion ratio was higher in cirrhotic patients with ascites as compared to those without ascites (median 0.12 , range $0-0.83 \mathrm{mmol}$ vs. median 0.07 , range $0-0.87 \mathrm{mmol}$; $\mathrm{p}=0.04$ (Figure 2). Nineteen of $27(70.3 \%)$ cirrhotic patients with ascites had an abnormal urinary lctulose/mannitol excretion ratio as compared to 21/44 $(47.7 \%)$ patients without ascites $(\mathrm{p}=0.06)$.

Factors associated with abnormal urinary lactulosel mannitol excretion ratio on univariate and multivariate analysis

Factors associated with normal and abnormal SIP are given in Tables 3 and 4. On univariate analysis, patients with abnormal urinary lactulose/mannitol excretion ratio more often had

Table 2: Urinary lactulose/mannitol excretion ratio in patients with EHPVO and cirrhosis

\begin{tabular}{llll}
\hline $\begin{array}{l}\text { Urinary excretion } \\
\text { after } 6 \text { hours }\end{array}$ & $\begin{array}{l}\text { EHPVO } \\
(\mathbf{n = 2 5})\end{array}$ & $\begin{array}{l}\text { Cirrhosis } \\
(\mathbf{n = 7 1})\end{array}$ & p value* \\
\hline $\begin{array}{l}\text { Lactulose excretion } \\
\text { (mmol) }\end{array}$ & $0.28(0-1.93)$ & $0.87(0-20.32)$ & 0.007 \\
$\begin{array}{l}\text { Mannitol excretion } \\
(\mathrm{mmol})\end{array}$ & $8.97(0-28.54)$ & $11.38(0-100.82)$ & 0.109 \\
$\begin{array}{l}\text { Lactulose/mannitol } \\
\text { ratio (mmol) }\end{array}$ & $0.05(0-0.19)$ & $0.09(0-0.87)$ & 0.008 \\
\hline *Mann-Whitney Utest & & & \\
EHPVO extrahepatic portal venous obstruction &
\end{tabular}




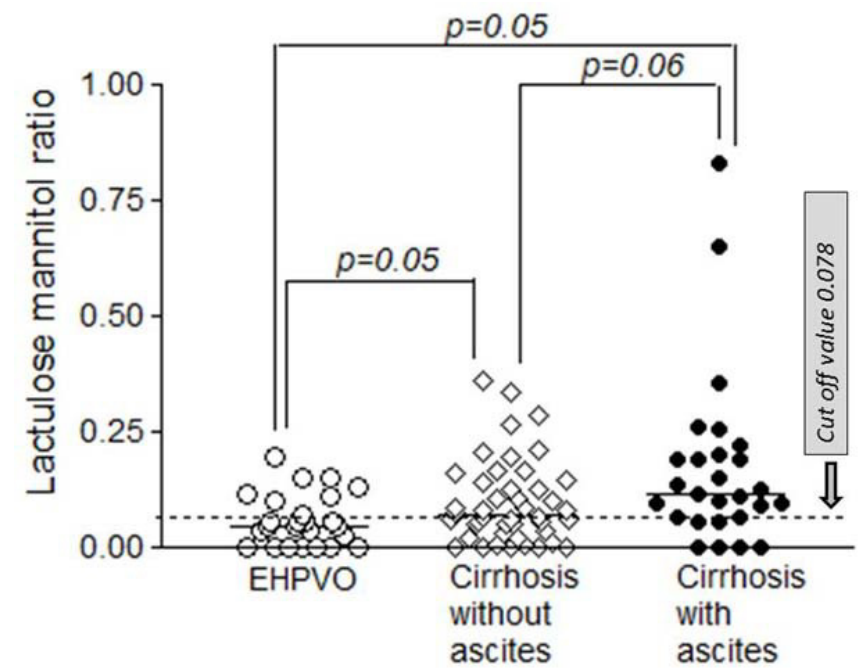

Figure 2: Lactulose/mannitol ratio in healthy controls, EHPVO, cirrhosis without ascites and cirrhosis with ascites EHPVO=extrahepatic portal venous obstruction cirrhosis, ascites, higher Child score, serum bilirubin level, serum alkaline phosphate and prothrombin time (Table 3). On multivariate analysis, the presence of cirrhosis, ascites, high serum bilirubin level and prothrombin time were associated with abnormal SIP (Table 4).

\section{Discussion}

In the present study, $49 \%$ of patients with PHT had abnormal SIP, and those with cirrhosis more often had abnormal SIP than EHPVO. Patients with abnormal SIP had a higher Child score and more often had cirrhosis than EHPVO, ascites and deranged liver function. On multivariate analysis, the presence of cirrhosis, ascites, high serum bilirubin level and prothrombin time were associated with abnormal SIP.

Table 3: Demographic and clinical parameters of patients with abnormal and normal intestinal permeability

\begin{tabular}{|c|c|c|c|}
\hline Parameter & $\begin{array}{l}\text { Patients with abnormal } \\
\text { intestinal permeability } \\
(n=47)\end{array}$ & $\begin{array}{l}\text { Patients with normal } \\
\text { intestinal permeability } \\
(n=49)\end{array}$ & p value* \\
\hline Age (years) & $38(16-53)$ & $38(20-54)$ & 0.545 \\
\hline Gender (Men, \%) & $36(76.6 \%)$ & $34(69.4)$ & 0.495 \\
\hline Cirrhosis & $40(85.1)$ & $31(63.3)$ & 0.020 \\
\hline Alcoholism & $12(25.5)$ & $8(16.3)$ & 0.320 \\
\hline Presence of ascites & $19(40.4)$ & $8(16.3)$ & 0.012 \\
\hline $\mathrm{Hb}(\mathrm{g} / \mathrm{dL})$ & $10.9(4.9-14.8)$ & $10.7(6.7-15.9)$ & 0.806 \\
\hline Oesophageal varix & $34(72.3)$ & $34(69.4)$ & 0.824 \\
\hline BMI $\left(\mathrm{kg} / \mathrm{m}^{2}\right)$ & $22.5(14.3-33.0)$ & $20.5(15.4-30.5)$ & 0.201 \\
\hline Serum albumin $(\mathrm{g} / \mathrm{dL})$ & $3.6(1.5-4.9)$ & $3.7(0.6-4.6)$ & 0.705 \\
\hline Serum bilirubin $(\mathrm{mg} / \mathrm{dL})$ & $1.6(0.5-22.2)$ & $1.1(0.1-25.0)$ & 0.015 \\
\hline Aspartate aminotransferase (IU/L) & $51(15-309)$ & $42(21-558)$ & 0.205 \\
\hline Alanine aminotransferase (IU/L) & $35(10-215)$ & $34(21-401)$ & 0.997 \\
\hline Serum alkaline phosphate (IU/L) & $211(78-759)$ & $167(80-613)$ & 0.038 \\
\hline Prothrombin time (seconds) & $15.1(13-64)$ & $14.3(10.5-43.6)$ & 0.015 \\
\hline Child score & $6(5-13)$ & $5(5-13)$ & 0.030 \\
\hline
\end{tabular}

*Mann-Whitney U test for continuous variables, Chi-square test for categorical data

EHPVO=extrahepatic portal venous obstruction; BMI=body mass index; Hb=haemoglobin

All continuous data are presented as median and range. For categorical data, figures within parentheses indicate percentages.

Table 4: Multivariate analysis of factors predicting abnormal intestinal permeability

\begin{tabular}{llll}
\hline Parameter & Crude OR (95\% CI) & Adjusted OR (95\% CI) & p(LR-test) \\
\hline Gender & $0.693(0.279,1.718)$ & $0.719(0.236,2.190)$ & 0.5592 \\
Age (years) & $1.011(0.966,1.059)$ & $0.967(0.910,1.029)$ & 0.2798 \\
Aetiology: EHPVO vs. cirrhosis & $0.301(0.112,0.812)$ & $0.012(0,0.807)$ & 0.0318 \\
Alcohol & $0.569(0.209,1.550)$ & $0.979(0.259,3.706)$ & 0.9749 \\
Child score & $1.161(1.034,1.305)$ & $0.540(0.252,1.155)$ & 0.0978 \\
Ascites & $3.478(1.337,9.043)$ & $32.350(1.236,846.824)$ & 0.0241 \\
Oesophageal varices & $1.154(0.478,2.787)$ & $0.902(0.307,2.651)$ & 0.8510 \\
Serum bilirubin (mg/dL) & $0.993(0.904,1.092)$ & $0.843(0.694,1.025)$ & 0.0409 \\
Prothrombin time (seconds) & $1.052(0.971,1.139)$ & $1.145(0.986,1.330)$ & 0.0319 \\
Serum alkaline phosphate (IU/L) & $1.0027(0.999,1.006)$ & $1.0014(0.9972,1.0057)$ & 0.5039 \\
\hline
\end{tabular}

EHPVO=extrahepatic portal vein obstruction; OR=odds ratio; LR-test=likelihood ratio test 
Demonstration of normal SIP in patients with EHPVO may help to understand the mechanism of increased SIP in patients with PHT including those with cirrhosis of liver. Abnormal SIP in patients with cirrhosis might be related to PHT with consequent mucosal oedema or liver dysfunction. Only one study has been reported earlier on SIP among 11 children with EHPVO, who had normal permeability, as determined by urinary melibiose/rhammnose excretion ratio. ${ }^{14}$ In contrast, patients with cirrhosis had abnormal SIP. ${ }^{9,17}$ In an earlier study, it was found that the urinary lactulose/mannitol excretion ratio was higher in 80 patients with cirrhosis than in 28 controls. ${ }^{9}$ Another study also reported higher intestinal permeability in 35 patients with cirrhosis as compared to 6 healthy volunteers using urinary lactulose/rhammnose excretion ratio. ${ }^{17}$ The results of the present study on patients with cirrhosis are in accordance with the earlier studies..$^{9,17}$

The present study is perhaps the first report comparing SIP in adult patients with EHPVO and cirrhosis. Though about half of the patients with cirrhosis of liver had increased SIP based on a cut-off determined in an earlier study by our group, ${ }^{15}$ patients with EHPVO had normal SIP. These data are in accordance with an earlier study on small number of children with cirrhosis and EHPVO. ${ }^{14}$ These findings suggest that increased SIP in patients with cirrhosis is primarily due to hepatic dysfunction rather than due to PHT. This is further supported by studies that showed increased SIP in patients with acute viral hepatitis, which is associated with hepatic dysfunction but not PHT. ${ }^{18,19}$

Factors associated with abnormal SIP in patients with cirrhosis of liver included presence of ascites, high serum bilirubin level and prothrombin time, which are the markers of hepatic dysfunction. This is in accordance with an earlier study that reported abnormal intestinal permeability (polyethylene glycol 400 and 3350 retrieval in 8-hour urine samples) in patients with cirrhosis and ascites as compared to those without ascites or healthy subjects. ${ }^{11}$ Keshavarzian et al. found that alcoholics with chronic liver disease had a higher urinary lactulose/ mannitol excretion ratio though alcoholics with no liver disease and non-alcoholics with liver disease showed a normal urinary lactulose/mannitol excretion ratio. ${ }^{8}$ In our study, however, alcoholism was not associated with abnormal SIP. It is important to note that this may be related to type II statistical error due to small sample size of alcoholic patients.

The pathogenesis of increased SIP in patients with liver disease is uncertain. Abnormal SIP was also reported in several other diseases, which primarily affect small intestinal mucosa such as coeliac disease,${ }^{20}$ Crohn's disease, ${ }^{21}$ small intestinal bacterial overgrowth (SIBO), ${ }^{22,23}$ and tropical sprue. ${ }^{5}$ In these conditions, abnormal SIP might be due to direct damage to intestinal epithelial cells and the tight junctions between these cells. $^{24,25}$ In patients with cirrhosis of liver, however, damage to the tight junctions in the small intestinal epithelium might be related to retention of substances that are toxic to small intestinal mucosa, which are normally metabolized by the healthy liver. Pro-inflammatory cytokines may be one group of such substances, which are known to cause an increase in SIP. ${ }^{26}$ In vitro studies in cell monolayers suggest that cytokines might mediate the permeation effects by changing the production of nitric oxide, ${ }^{27}$ possibly resulting from oxidation and nitration of cytoskeleton proteins. ${ }^{28}$ In a normal small intestinal epithelium, the tight junction between two cells prevents the entry of lactulose ${ }^{29,30}$ in contrast, in disease states associated with increased SIP, a leaky tight junction permits the entry of a large molecule such as lactulose..$^{31,32}$ The findings showing higher frequency of abnormal SIP in patients with higher grades of liver dysfunction support our contention. It has also been suggested previously that the severity of the small intestinal disease might correlate with the degree of abnormality of SIP. ${ }^{33}$ Another possible pathogenesis of abnormal SIP in patients with cirrhosis of the liver might be related to SIBO, which occurs frequently in patients with cirrhosis of the liver but not in patients with EHPVO. ${ }^{34}$

Increased SIP in patients with cirrhosis may have clinical importance. This condition may predispose to translocation of bacteria from the small bowel leading to endotoxaemia, septicaemia and spontaneous bacterial peritonitis. ${ }^{12}$ Further studies are required to evaluate whether altered intestinal permeability may have a role in progression of cirrhosis and whether onset of complications such as hepatic encephalopathy and ascites in patients with cirrhosis can be prevented or delayed by altering intestinal permeability? Increased SIP in patients with cirrhosis may predispose to translocation of enteric bacteria, especially in the presence of SIBO ${ }^{35}$ leading to development of spontaneous bacterial peritonitis. Also, increased intestinal permeability has been found in patients with cirrhosis and severe infectious complications. ${ }^{9}$ It has also been suggested that increased SIP may influence the progression of liver disease and development of complications such as hepatic encephalopathy ${ }^{10}$ and ascites. ${ }^{11}$ Patients with cirrhosis are often malnourished. Several pathophysiological mechanisms may contribute to malnutrition in such patients. Abnormal SIP may contribute to this as in 
other diseases such as tropical sprue; also, abnormal SIP has been shown to be associated with malnutrition. ${ }^{5}$ Increased permeability of intestinal tight junctions, retention of endotoxin and increased apoptosis have been implicated in the pathogenesis of primary biliary cirrhosis ${ }^{36}$ and alcoholic cirrhosis. $^{8}$

In an earlier study, our group standardized the estimation of lactulose and mannitol in urine by $1 \mathrm{H}-\mathrm{NMR}$ spectroscopy for assessment of SIP. ${ }^{15}$ Two cut-off values were presented for urinary lactulose/mannito/excretion ratio - a value of $0.078 \mathrm{had}$ $67 \%$ sensitivity and $90 \%$ specificity, and a value of 0.049 had $72 \%$ sensitivity and $61 \%$ specificity. In our study, we took 0.078 as the cut-off value because it has higher specificity.

In conclusion, increased SIP is frequent in patients with cirrhosis of the liver and is related to the degree of liver dysfunction as assessed by the degree of derangement in liver function including the Child score and presence of ascites. SIP, however, was normal in patients with EHPVO — a condition in which PHT occurs in the absence of significant liver dysfunction. These findings suggest that liver dysfunction underlie the occurrence of increased SIP than PHT.

\section{References}

1. Arrieta MC, Bistritz L, Meddings JB. Alterations in intestinal permeability. Gut. 2006;55:1512-20.

2. Duerksen DR, Wilhelm-Boyles C, Parry DM. Intestinal permeability in long-term follow-up of patients with celiac disease on a gluten-free diet. Dig Dis Sci. 2005;50:785-90.

3. Irvine EJ, Marshall JK. Increased intestinal permeability precedes the onset of Crohn's disease in a subject with familial risk. Gastroenterology. 2000;119:1740-4.

4. Marshall JK, Thabane M, Garg AX, Clark W, Meddings J, Collins SM, WEL Investigators. Intestinal permeability in patients with irritable bowel syndrome after a waterborne outbreak of acute gastroenteritis in Walkerton, Ontario. Aliment Pharmacol Ther. 2004;20:1317-22.

5. Kumar S, Ghoshal UC, Jayalakshmi K, Roy R, Misra A, Khetrapal CL. Abnormal small intestinal permeability in patients with idiopathic malabsorption in tropics (tropical sprue) does not change even after successful treatment. Dig Dis Sci. 2011;56:161-9.

6. Ersöz G, Aydin A, Erdem S, Yüksel D, Akarca U, Kumanlioglu K. Intestinal permeability in liver cirrhosis. Eur J Gastroenterol Hepatol. 1999;11:409-12.

7. Zuckerman MJ, Menzies IS, Ho H, Gregory GG, Casner NA, Crane RS, et al. Assessment of intestinal permeability and absorption in cirrhotic patients with ascites using combined sugar probes. Dig Dis Sci. 2004;49:621-6.

8. Keshavarzian A, Holmes EW, Patel M, Iber F, Fields JZ, Pethkar S. Leaky gut in alcoholic cirrhosis: a possible mechanism for alcohol-induced liver damage. Am J Gastroenterol. 1999;94:200-7.

9. Campillo B, Pernet P, Bories PN, Richardet JP, Devanlay $\mathrm{M}$, Aussel C. Intestinal permeability in liver cirrhosis: relationship with severe septic complications. Eur J Gastroenterol Hepatol. 1999;11:755-9.

10. Pascual S, Such J, Esteban A, Zapater P, Casellas JA, Aparicio $\mathrm{JR}$, et al. Intestinal permeability is increased in patients with advanced cirrhosis. Hepatogastroenterology. 2003;50:1482-6.

11. Lee S, Son SC, Han MJ, Kim WJ, Kim SH, Kim HR, et al. Increased intestinal macromolecular permeability and urine nitrite excretion associated with liver cirrhosis with ascites. World $J$ Gastroenterol. 2008;14:3884-90.

12. Farhadi A, Banan A, Fields J, Keshavarzian A. Intestinal barrier: an interface between health and disease. J Gastroenterol Hepatol. 2003;18:479-97.

13. Crossley IR, Williams R. Spontaneous bacterial peritonitis. Gut. 1985;26:325-31.

14. Taylor RM, Bjarnason I, Cheeseman P, Davenport M, Baker AJ, Mieli-Vergani G, et al. Intestine permeability and absorptive capacity in children with portal hypertension. Scand $J$ Gastroenterol. 2002;37:807-11.

15. Jayalakshmi K, Ghoshal UC, Kumar S, Misra A, Roy R, Khetrapal CL. Assessment of small intestinal permeability using 1H-NMR spectroscopy. J Gastrointestin Liver Dis. 2009;18:27-32.

16. Mayer J, Conrad J, Klaiber I, Lutz-Wahl S, Beifuss U, Fischer L. Enzymatic production and complete nuclear magnetic resonance assignment of the sugar lactulose. J Agric Food Chem. 2004;52:6983-90.

17. Fujii T, Seki T, Maruoka M, Tanaka J, Kawashima Y, Watanabe $\mathrm{T}$, et al. Lactulose-L-rhamnose intestinal permeability test in patients with liver cirrhosis. Hepatol Res. 2001;19:158-69.

18. Parrilli G, Cuomo R, Nardone G, Maio G, Izzo CM, Budillon G. Investigation of intestinal function during acute viral hepatitis using combined sugar oral loads. Gut 1987;28:1439-44.

19. Welsh FK, Ramsden CW, MacLennan K, Sheridan MB, Barclay GR, Guillou PJ, et al. Increased intestinal permeability and altered mucosal immunity in cholestatic jaundice. Ann Surg. 1998;227:205-12.

20. Ukabam SO, Cooper BT. Small intestinal permeability as an indicator of jejunal mucosal recovery in patients with celiac sprue on a gluten-free diet. J Clin Gastroenterol. 1985;7:232-6.

21. Ukabam SO, Clamp JR, Cooper BT. Abnormal small intestinal permeability to sugars in patients with Crohn's disease of the terminal ileum and colon. Digestion. 1983;27:70-4.

22. Riordan SM, Duncombe VM, Thomas MC, Nagree A, Bolin TD, McIver CJ, et al. Small intestinal bacterial overgrowth, intestinal permeability, and non-alcoholic steatohepatitis. Gut. 2002;50:136-8.

23. Morris TH, Sorensen SH, Turkington J, Batt RM. Diarrhoea and increased intestinal permeability in laboratory beagles associated with proximal small intestinal bacterial overgrowth. Lab Anim. 1994;28:313-19.

24. Hossain Z, Hirata T. Molecular mechanism of intestinal permeability: interaction of tight junctions. Mol Biosyst. 2008;4:1181-5. 
25. Vellenga L, Mouwen JM, van Dijk JE, Breukink HJ. Biological and pathological aspects of the mammalian small intestinal permeability to macromolecules. Vet $Q .1985 ; 7: 322-32$.

26. McKay DM, Baird AW. Cytokine regulation of epithelial permeability and ion transport. Gut. 1999;44:283-9.

27. Wallace JL, Miller MJ. Nitric oxide in mucosal defense: a little goes a long way. Gastroenterology. 2000;119:512-20.

28. Banan A, Fields JZ, Zhang Y, Keshavarzian A. iNOS upregulation mediates oxidant-induced disruption of F-actin and barrier of intestinal monolayers. Am J Physiol Gastrointest Liver Physiol. 2001;280:1234-46.

29. Akinbami FO, Brown GA, McNeish AS. Intestinal permeability as a measure of small intestinal mucosal integrity: correlation with jejunal biopsy. Afr J Med Med Sci. 1989;18:187-92.

30. Ballard ST, Hunter JH, Taylor AE. Regulation of tight-junction pereability during nutrient absorption across the intestinal epithelium. Annu Rev Nutr. 1995;15:35-55.

31. Madara JL, Marcial MA. Structural correlates of intestinal tight- junction permeability. Kroc Found Ser. 1984;17:77-100.

32. Perry MA, Granger DN. Permeability of intestinal capillaries to small molecules. Am J Physiol. 1981;241:24-30.

33. Brunetto AL, Pearson AD, Laker MF, Craft AW. Intestinal permeability tests and integrity of the small intestinal mucosa. Arch Dis Child. 1989;64:307-8.

34. Lakshmi CP, Ghoshal UC, Kumar S, Goel A, Misra A, Mohindra $\mathrm{S}$, et al. Frequency and factors associated with small intestinal bacterial overgrowth in patients with cirrhosis of the liver and extra hepatic portal venous obstruction. Dig Dis Sci. 2010;55:1142-8.

35. Chesta J, Defilippi C, Defilippi C. Abnormalities in small bowel motility in patients with cirrhosis. Hepatology. 1993;17:828-32.

36. Sakisaka S, Koga H, Sasatomi K, Mimura Y, Kawaguchi T, Tanikawa K. Biliary secretion of endotoxin and pathogenesis of primary biliary cirrhosis. Yale J Biol Med. 1997;70:403-8. 